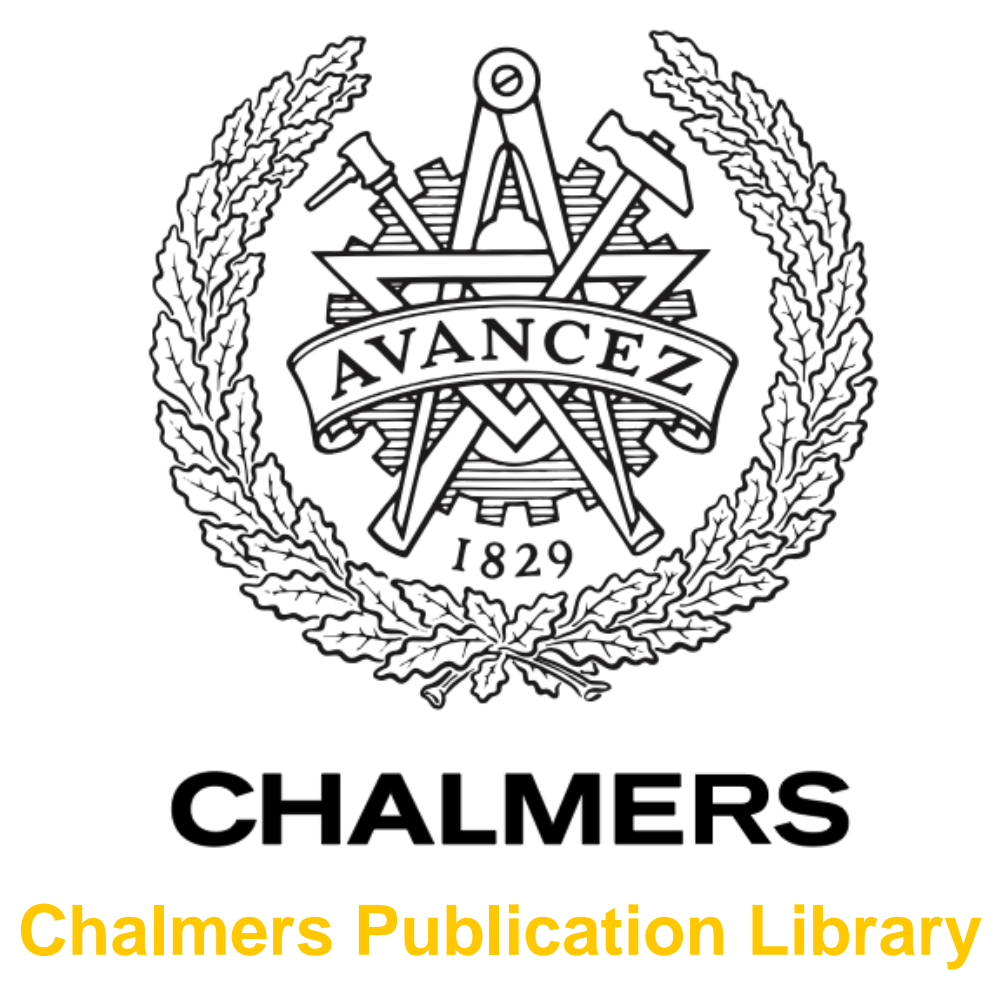

\title{
2D Bipyrimidine silver(I) nitrate: Synthesis, X-ray structure, solution chemistry and anti-microbial activit
}

This document has been downloaded from Chalmers Publication Library (CPL). It is the author's version of a work that was accepted for publication in:

Inorganic Chemistry Communications (ISSN: 1387-7003)

Citation for the published paper:

Massoud, A. ; Langer, V. ; Gohar, Y. (2011) "2D Bipyrimidine silver(I) nitrate: Synthesis, Xray structure, solution chemistry and anti-microbial activit". Inorganic Chemistry

Communications, vol. 14(4), pp. 550-553.

http://dx.doi.org/10.1016/j.inoche.2011.01.022

Downloaded from: http://publications.lib.chalmers.se/publication/138551

Notice: Changes introduced as a result of publishing processes such as copy-editing and formatting may not be reflected in this document. For a definitive version of this work, please refer to the published source. Please note that access to the published version might require a subscription.

Chalmers Publication Library (CPL) offers the possibility of retrieving research publications produced at Chalmers University of Technology. It covers all types of publications: articles, dissertations, licentiate theses, masters theses, conference papers, reports etc. Since 2006 it is the official tool for Chalmers official publication statistics. To ensure that Chalmers research results are disseminated as widely as possible, an Open Access Policy has been adopted.

The CPL service is administrated and maintained by Chalmers Library. 


\title{
2D Bipyrimidine silver(I) nitrate: synthesis, $X$-ray structure, solution chemistry and anti-microbial activity
}

\author{
Alshima'a A. Massoud*a ${ }^{a}$, Vratislav Langer ${ }^{a}$, Yousry M. Gohar ${ }^{b}$, Morsy A. Abu-Youssef ${ }^{c}$, Janne \\ Jänis ${ }^{\mathrm{d}}$ and Lars Öhrström*a
}

${ }^{a}$ Dept. of Chemical and Biological Engineering, Chalmers University of Technology, SE-412 96 Göteborg, Sweden. Fax: +46 31

772 3858; E-mail: shimo@ chalmers.se; langer@ chalmers.se; ohrstrom@chalmers.se; Tel: +46 31772 3050;

${ }^{b}$ Dept. of Microbiology, P.O. Box 426 Ibrahimia, 21321 Alexandria, Egypt; E-mail: ymgohar@yahoo.com

${ }^{c}$ Chemistry Dept., Alexandria University, P.O. Box 426 Ibrahimia, 21321 Alexandria, Egypt; E-mail: morsy5@link.net

${ }^{\mathrm{d}}$ Dept. of Chemistry, University of Eastern Finland, P.O. Box 111, FI-80101, Joensuu, Finland; E-mail: janne.janis@uef.fi

\begin{abstract}
Synthesis and X-ray single crystal structure analysis of the compound $\left\{\left[\mathrm{Ag}_{2}\left(\mu_{2}-\mathrm{bpym}\right)(\mu-\mathrm{O}-\right.\right.$ $\left.\left.\left.\mathrm{NO}_{3}\right)_{2}\right]\right\}_{n}$, (1), (where bpym = 2,2'-bipyrimidine) are presented. Compound (1) has a $(6,3)-2 \mathrm{D}$ honeycomb structure with a tetrahedral coordination geometry around the $\mathrm{Ag}(\mathrm{I})$ ion. In contrary to the solid state structural investigation, ESI-MS for (1) in solution shows a strong peak at $\mathrm{m} / z$ 423.0269 which indicates that the $\left[\mathrm{Ag}(\mathrm{bpym})_{2}\right]^{+}$cation is dominating instead of $\left[\mathrm{Ag}_{2}(\mathrm{bpym})\right]^{2+}$. The anti-microbial activity of (1) was screened against 15 multi-drug resistant bacteria in comparison to silver(I) sulphadiazine and it showed a high activity against Burkholderia mallei which causes glanders; with a MIC value of $4 \mu \mathrm{g} / \mathrm{ml}$.
\end{abstract}

Keywords: silver(I) compounds, 2,2'-bipyrimidine, X-ray structure, anti-microbial activity.

Polymeric silver(I) compounds have recently attracted a great interest as versatile components in supramolecular compounds, [1-4] for photoluminescent [5], medicinal [6] and anti-microbial purposes [7-12]. The latter application has a long history even predating the discovery of microorganisms, [13-14] and before the introduction of modern antibiotics, silver in various forms was used for several medical indications. Our research group has synthesized and structurally characterized a number of monomeric, dimeric and 1D silver(I) compounds with Ndonor heterocyclic ligands, most of which showed considerable anti-microbial activities against multi-drug resistant bacteria [15-22].

Since $\operatorname{Ag}(\mathrm{I})$ has the preference to form linear, trigonal planar or tetrahedral coordination geometries and often serves as simple spacer or connector (L-M-L coordination synthon), the geometry of the formed supramolecular structure depends mainly on the choice of polydentate 
ligand [23]. Here we have chosen 2,2'-bipyrimidine (bpym) as a bis-bidentate ligand which can bridge several metal centres.

Compound (1) was synthesized ${ }^{1}$ in a good crystalline form suitable for single crystal X-ray diffraction ${ }^{2}$ upon direct mixing of $\mathrm{AgNO}_{3}$ in water, and the corresponding organic ligand, (bpym) in ethanol, in a molar ratio $\mathrm{Ag}: \mathrm{L}=1: 2$. High resolution ESI-MS for (1) was performed in a DMSO/ $\mathrm{CH}_{3} \mathrm{OH}$ mixture to detect different cationic species in solution ${ }^{3}$. Antimicrobial activities of (1) are calculated as (MIC) values or Minimum Inhibitory Concentrations ${ }^{4}$.

The structure of $\left\{\left[\mathrm{Ag}_{2}\left(\mu_{2}-\mathrm{bpym}\right)\left(\mu-\mathrm{O}-\mathrm{NO}_{3}\right)_{2}\right]\right\}_{n}$ is shown in Fig. 1. The bpym ligand is $\left(\mu_{2^{-}}\right.$ $\mathrm{N} 1, \mathrm{~N} 1^{\mathrm{i}}, \mathrm{N} 2, \mathrm{~N} 2^{\mathrm{i}}$ ) chelating and bridging two silver(I) ions via its four nitrogen atoms forming two five-membered rings $\mathrm{Ag} 1 / \mathrm{N} 1 / \mathrm{C} 2 / \mathrm{C} 2^{\mathrm{i}} / \mathrm{N} 2^{\mathrm{i}}$ and $\mathrm{N} 2 / \mathrm{C} 2 / \mathrm{C} 2^{\mathrm{i}} / \mathrm{N} 1^{\mathrm{i}} / \mathrm{Ag} 1^{\mathrm{i}}$. Each silver(I) atom is further coordinated to two nitrate groups forming a distorted tetrahedron defined by N1/N2 ${ }^{\mathrm{i}} / \mathrm{O} 33 / \mathrm{O} 33^{\mathrm{iii}}$. A CSD search [24] revealed 333 structures for bpym with different transition metals while only four $\mathrm{Ag}(\mathrm{I})$ structures were found: $\left[\mathrm{Ag}_{4}(\mathrm{hfac})_{4}\left(\mu_{2}-\mathrm{bpym}\right)_{3}\right],[25]\left\{\left[\mathrm{Ag}\left(\mu_{2}-\mathrm{bpym}\right)\right]\right\}_{n} \cdot \mathrm{nClO} \mathrm{O}_{4},[25]$ $\left\{\left[\mathrm{Ag}_{2}\left(\mu_{2}-\mathrm{bpym}\right)\left(\mu_{2}-\mathrm{ox}\right)\right]\right\}_{n} \cdot 4 \mathrm{nH}_{2} \mathrm{O}[25]$ and $\left[\mathrm{Ag}\left(\mu_{2}\right.\right.$-bpym) $]\left[\mathrm{Cr}\left(\mu_{2}-\mathrm{ox}\right)_{2}\left(\mathrm{H}_{2} \mathrm{O}\right)_{2}\right] .2 \mathrm{H}_{2} \mathrm{O}$ [26] (where hfac $=1,1,1,5,5,5$-hexafluoroacetylacetonate and ox $=$ the oxalate anion $\left.\mathrm{C}_{2} \mathrm{O}_{4}{ }^{2-}\right) . \quad\left[\mathrm{Ag}_{4}\left(\mathrm{hfac}_{4}\left(\mu_{2^{-}}\right.\right.\right.$ bpym $)_{3}$ ] is a tetramer with two distorted square planar and two trigonal prismatic $\mathrm{Ag}(\mathrm{I})$ atoms, while compounds $\left\{\left[\mathrm{Ag}\left(\mu_{2} \text {-bpym }\right)\right]\right\}_{n} \cdot \mathrm{nClO}_{4}$ and $\left[\mathrm{Ag}\left(\mu_{2}\right.\right.$-bpym $\left.)\right]\left[\mathrm{Cr}\left(\mu_{2}-\mathrm{ox}\right)_{2}\left(\mathrm{H}_{2} \mathrm{O}\right)_{2}\right] .2 \mathrm{H}_{2} \mathrm{O}$ have both $1 \mathrm{D}$ structure consisting of $\left[\mathrm{Ag}\left(\mu_{2}-\mathrm{bpym}\right)\right]^{+}$repeating units where the bpym ligand is chelating and bridging two $\mathrm{Ag}(\mathrm{I})$ atoms. The compound $\left\{\left[\mathrm{Ag}_{2}\left(\mu_{2}-\mathrm{bpym}\right)\left(\mu_{2}-\mathrm{ox}\right)\right]\right\}_{n} \cdot 4 \mathrm{nH}_{2} \mathrm{O}$ also has a $1 \mathrm{D}$ structure where $\left[\mathrm{Ag}_{2}\left(\mu_{2} \text {-bpym) }\right]^{2+}\right.$ cationic units are connected by oxalate anions $\left(\mathrm{C}_{2} \mathrm{O}_{4}\right)^{2-}$. Selected bond lengths and angles for $(\mathbf{1})$ are listed together with comparable structures

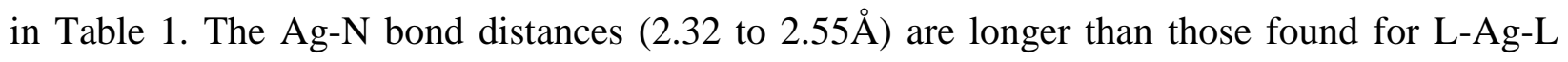
linear compounds [18-19] and are correlated to small $\mathrm{N}-\mathrm{Ag}-\mathrm{N}$ chelation angles for all these compounds $\left(65\right.$ to $\left.72^{\circ}\right)$.

Weak interactions between the $\mathrm{Ag}(\mathrm{I})$ ion and adjacent oxygen atoms are also found; $\mathrm{Ag} . . \mathrm{O} 32$ and $\mathrm{Ag} . . . \mathrm{O} 33^{\mathrm{ii}}$ are 2.981(6) and 2.989(5) $\mathrm{A}$, respectively [Symmetry codes: (i) -x, 1-y, -z; (ii) 1/2$\mathrm{x},-1 / 2+\mathrm{y}, 1 / 2-\mathrm{z}$ and (iii) $1 / 2-\mathrm{x}, 1 / 2+\mathrm{y}, 1 / 2-\mathrm{z}]$. The nitrate groups act as $(\mu-\mathrm{O})$ bridging $\mathrm{Ag}(\mathrm{I})$ ions through one oxygen atom (O33) to form 1D helices in b direction, see Fig. 2, with a weak interaction between the superimposed $\mathrm{Ag}(\mathrm{I})$ ions; $\mathrm{Ag} \ldots \mathrm{Ag}^{\mathrm{v}}$ and $\mathrm{Ag} \ldots \mathrm{Ag}^{\mathrm{vi}}$ is $3.5204(6) \AA$, [symmetry codes: (v) x, $-1+\mathrm{y}, \mathrm{z}$ and (vi) $\mathrm{x}, 1+\mathrm{y}, \mathrm{z}$ ]. Similar helices are found for the compound $\left[\mathrm{Ag}\left(2,2^{\prime} \text {-bipyridine }\right)\left(\mathrm{NO}_{3}\right)\right]_{n}[27]$ where nitrate groups are bridging the $\left[\mathrm{Ag}\left(2,2^{\prime} \text {-bipyridine }\right)\right]^{+}$ 
units to form 1D chain of molecules with no Ag...Ag interactions. In case of (1) both bridging bpym ligands and nitrate groups extend the structure to $(6,3)-2 \mathrm{D}$ honeycomb sheet (considering $\operatorname{Ag}(\mathrm{I})$ ions as nodes) in (b, c)- plane, see Fig. 3. Strong $\pi-\pi$ stacking between the five-membered rings and the pyrimidine rings of same sheet is found, while no interactions between the pyrimidine rings themselves could be found; centroid-centroid distances are 3.520(2) and $3.390(3) \AA$ with $\beta$ angles (offset angle) 23 and $17^{\circ}$, respectively.

ESI-MS is a technique used for detection of different ionic species (cations or anions) possibly present in solution and/or in gas-phase and account for their relative stabilities under experimental conditions [28]. For compound (1), a very strong peak is observed at $\mathrm{m} / \mathrm{z} 423.0269$ which is consistent with the calculated value for $\left[\mathrm{Ag}(\mathrm{bpym})_{2}\right]^{+}\left(423.02\right.$ for $\left.\mathrm{C}_{16} \mathrm{H}_{12} \mathrm{AgN}_{8}{ }^{+}\right)$instead of the expected cation $\left[\mathrm{Ag}_{2}(\mathrm{bpym})\right]^{2+}$ found in the solid-state structure. Two minor peaks are also detected at $m / z \quad 264.9670$ and 591.9208 which can be assigned to $[\mathrm{Ag}(\mathrm{bpym})]^{+}$and $\left[\mathrm{Ag}_{2}(\text { bpym })_{2}\left(\mathrm{NO}_{3}\right)\right]^{+}$cations; calculated values are 264.96 and 591.92 for $\mathrm{C}_{8} \mathrm{H}_{6} \mathrm{AgN}_{4}{ }^{+}$and $\mathrm{C}_{16} \mathrm{H}_{12} \mathrm{Ag}_{2} \mathrm{~N}_{9} \mathrm{O}_{3}{ }^{+}$, respectively. Also, the observation of a characteristic ${ }^{107} \mathrm{Ag} /{ }^{109} \mathrm{Ag}$ isotopic peak doublet $(\sim 52: 48)$ further identified the 1:2 compound [29].

The compound in solution thus prefers the stoichiometry 1:2 (Ag:L) with a suggested tetrahedral coordination geometry around the $\mathrm{Ag}(\mathrm{I})$ ion as found in the previously mentioned compounds $\left\{\left[\mathrm{Ag}\left(\mu_{2}-\mathrm{bpym}\right)\right]\right\}_{n} \cdot \mathrm{nClO}{ }_{4}$ and $\left\{\left[\mathrm{Ag}_{2}\left(\mu_{2}-\mathrm{bpym}\right)\left(\mu_{2}-\mathrm{ox}\right)\right]\right\}_{n} \cdot 4 \mathrm{nH}_{2} \mathrm{O}$ [25]. The nitrate coordination to the $\operatorname{Ag}(\mathrm{I})$ centres in (1) is stabilizing the sheets formed in the solid-state with the stoichiometry 2:1 (Ag:L) while in solution the nitrates have been solvated giving the ligand more chance to directly attack the half naked $[\mathrm{Ag}(\mathrm{bpym})]^{+}$and form the $1: 2(\mathrm{Ag}: \mathrm{L})$ cation $\left[\mathrm{Ag}(\mathrm{bpym})_{2}\right]^{+}$.

In some related studies the ESI-MS of the silver(I) trifluoromethan sulfonate $\left(\mathrm{AgO}_{3} \mathrm{SCF}_{3}\right)$ compound with 3,6-di(2-pyridyl)pyridazine in $\mathrm{CH}_{3} \mathrm{CN}$ were consistent with $\mathrm{X}$-ray crystallography where the same cations $\left[\operatorname{Ag}(L)_{2}\right]^{+}(\mathrm{Ag}: \mathrm{L}=1: 2)$ were found [30]. Similarly, the ESI-MS for the compound [ $\left.\mathrm{Ag}(4,5 \text {-diazafluoren-9-one })_{2}\right] \mathrm{NO}_{3}$ [21] showed only one strong peak representing the complex $\left[\mathrm{Ag}(\mathrm{L})_{2}\right]^{+}$with $(\mathrm{Ag}: \mathrm{L}=1: 2)$. On the contrary, the ESI-MS for a solution containing $\mathrm{AgBF}_{4}$ and excess bidentate 1,12-diazaperylene ligand indicate the formation of the 1:1 (90\%) Ag:L complex while the expected 1:2 complex is only observed as a minor peak (10\%) [31]. Thus the complexation behaviour of silver(I) ions in solution is complicated.

Compound (1) shows activities comparable with the commercially used silver(I) sulphadiazine against most Gram-positive bacteria used in this test, MIC values are listed in Table 2. The 
highest activity recorded for (1) was against the Gram-negative Burkholderia mallei which causes glanders [32]; MIC value $4 \mu \mathrm{g} / \mathrm{ml}$.

In conclusion, we have synthesized and structurally characterized the compound $\left\{\left[\operatorname{Ag}_{2}\left(\mu_{2^{-}}\right.\right.\right.$ bpym) $\left.\left.\left(\mu-\mathrm{O}-\mathrm{NO}_{3}\right)_{2}\right]\right\}_{n}$. The compound shows a broad spectrum antibacterial activity against all the test organisms with stronger effect against the Gram-negative Burkholderia mallei than silver(I) sulphadiazine under the same test conditions. This activity should be interpreted on the bases of solution chemistry of the compound, where $\left[\mathrm{Ag}(\mathrm{bpym})_{2}\right]^{+}$cation is detected by ESI-MS.

\section{Acknowledgements}

This work was supported by Kristina Stenborgs Stiftelse, Magnus Bergvalls stiftelse and Kungliga Vetenskaps och Vitterhetssamhället i Göteborg. The authors thank Mr. Jakub Večerka for X-ray data collection and treatment and Mrs. Ritva Romppanen for her skilful technical assistance in ESI-MS measurements. AAM thanks the NORDFORSK network in Crystal Engineering and Supramolecular Materials for a travel grant to Joensuu.

\section{Supplementary material}

A Table and a Figure for weak C-H...O interactions are available. CCDC 797352 contains the supplementary crystallographic data for (1). These data can be obtained free of charge from the Cambridge Crystallographic Data Center via http://www.ccdc.cam.ac.uk/data_request/cif. 


\section{Notes and References}

${ }^{1}$ To an aqueous solution $\left(20 \mathrm{~cm}^{3}\right)$ of $\mathrm{AgNO}_{3}(0.34 \mathrm{~g}, 2.0 \mathrm{mmol})$, an ethanolic solution of $4 \mathrm{mmol}$ of 2,2'-bipyrimidine (0.60g) was added with continuous stirring. The mixture was then heated till boiling, followed by filtration. The clear filtrate was allowed to stand at room temperature for a couple of weeks. Colorless needles of (1) suitable for X-ray measurements were collected and dried in air, with a yield $\sim 85 \%$ with respect to $\mathrm{AgNO}_{3}$. IR was recorded on a Bruker IFS-125 model FT-IR spectrophotometer as KBr pellets; (v, very; s, strong; m, medium; w, weak; br, broad; sh, shoulder): 3090 s, 1609 w, 1560 vs, 1449 vs, 1408 sh, 1457 vs, br, 1283 vs, 1264 vs, 1142 m, 1104 m, 1015 s, 827 s, 807 m, 758 s, 685 w, 661 s, 593 m, 409 m, 388 m, 343 w, 317 w, 272 w. Elemental analyses $(\mathrm{C}, \mathrm{H}, \mathrm{N})$ were carried out by Mikroanalytisches Laboratorium KOLBE, Mülheim an der Ruhr, Germany. Calculated values are: C, 19.22; H, 1.61 and N, 16.81\%. Found values are: C, 19.17; H, 1.42 and $16.53 \%$.

${ }^{2}$ Crystallographic measurements were made on a Siemens Smart CCD diffractometer with graphite-monochromated Mo K $\alpha$ radiation $(\lambda=0.71073 \AA)$ at $153 \mathrm{~K}$. The structure was solved by direct method and subsequent full-matrix least-squares refinement, including anisotropic thermal parameters for all non-hydrogen atoms. Hydrogen atoms were refined isotropically with use of geometrical constrains. The calculations were carried out using SHELXTL program package. Empirical formula: $\mathrm{C}_{16} \mathrm{H}_{12} \mathrm{Ag}_{4} \mathrm{~N}_{12} \mathrm{O}_{12}$, F.W. 995.86, Crystal system: monoclinic, Space group: C2/c, a=20.940(2), b=3.5204(4), c=19.477(2) $\mathrm{A}$, $\beta=122.017(2)^{\circ}, V=1217.4(2) \AA^{3}, Z=2, D_{(\text {calc }}=2.177 \mathrm{Mg} / \mathrm{m}^{3}, \mu=3.262 \mathrm{~mm}^{-1}, \mathrm{~F}(000)=952$, Crystal size: $0.40 \times 0.08 \times 0.06 \mathrm{~mm}^{3}, \theta$ range: 2.31 to $25.05^{\circ}$, Index ranges: $-24<=\mathrm{h}<=24,-4<=\mathrm{k}<=4,-23<=1<=23$, Reflections collected: 3998 , Independent reflections: $1070[\mathrm{R}(\mathrm{int})=0.0440]$, Completeness to $\theta=25.05^{\circ}: 99.1 \%$, Absorption correction: multi-scan, $\mathrm{T}_{(\mathrm{Max})}=0.8283, \mathrm{~T}_{(\mathrm{min})}=0.3553$, Refinement method: full-matrix least-squares on $\mathrm{F}^{2}$, Data/ restraints/ parameters: 1070/ 0/ 100, Goodness-of-fit: 1.006, Final $\mathrm{R}$ indices $[\mathrm{I}>2 \sigma(\mathrm{I})]: \mathrm{R} 1=0.0537$ and $\mathrm{wR} 2=0.1604, \mathrm{R}$ indices (all data): $\mathrm{R} 1=0.0547$ and $\mathrm{wR} 2=0.1623$, largest diff. peak and hole: 1.935 and -2.232 e. $\AA^{-3}$.

${ }^{3}$ High-resolution ESI-MS analysis was performed on a Bruker APEX-Qe hybrid quadrupole Fourier transform ion cyclotron resonance (Q-FT-ICR) mass spectrometer, equipped with an Apollo-II ESI source and a 4.7-T superconducting magnet. We used as gentle conditions as possible to ascertain that the MS data would represent solution characteristics rather than dissociation products in the gas-phase. CapExit: $300 \mathrm{~V}$, Skimmer1: $12 \mathrm{~V}$, Ion-funnel1: $150 \mathrm{~V}$, Skimmer2: $10 \mathrm{~V}$, Ion-funnel2: $15 \mathrm{~V}$, Drying gas: $180{ }^{\circ} \mathrm{C}$, Drying gas: 5.0 bar and Nebul. Gas: 1.0 bar. The instrument was operated in positive ion mode only. Compound (1) was dissolved in DMSO and diluted with $\mathrm{MeOH}$. This solution was infused into the ESI source at a flow rate of $1.5 \mu 1 / \mathrm{min}$ and positive ions were detected. The instrument was operated with Bruker XMASS 7.0.8 software and spectra were processed/ analyzed with the use of Bruker Data Analysis 3.5 software.

${ }^{4}$ Antimicrobial activity of (1) was determined according to the recommendations of NCCLS (1999), National Committee for Clinical Laboratory Standard, by the use of broth microdilution method. Minimum inhibitory concentrations (MICs) for the tested compound were conducted using 15 different bacterial clinical isolates (Department of Vascular Surgery, Faculty of Medicine, Alexandria University, Egypt) and are all resistant strains for commonly used antibiotics. The test material was dissolved in DMSO to give a stock solution that subsequently diluted in the growth medium to give final concentrations of 256 , $128,64,32,16,8,2,1$, and $0.5 \mu \mathrm{g}$ of compound/ml. A final concentration of 5\% DMSO was present in all assays. Bacteria were cultured in Mueller Hinton broth (MHB) for $24 \mathrm{~h}$ at $35^{\circ} \mathrm{C}$. A toxicity bioassay against Daphnia was conducted using standard methods.

5 Table 2 footnote: The MIC values are corresponding to the lowest concentrations $(\mu \mathrm{g} / \mathrm{ml})$ that inhibited the bacterial growth. 
[1] E. Guney, V. T. Yilmaz, O. Buyukgungor, Inorg. Chem. Commu. 13 (2010) 563-567.

[2] N. Liang, J. Wang, D. Yuan, B. Li, H. Li, Inorg. Chem. Commu. 13 (2010) 844-846.

[3] S. Liao, C.-Y. Su, C.-H. Yeung, A.-W. Xu, H.-X. Zhang, H.-Q. Liu, Inorg. Chem. Commu. 3 (2000) 405-407.

[4] C.-J. Wang, Y.-Y. Wang, H. Wang, G.-P. Yang, G.-L. Wen, M. Zhang, Q.-Z. Shi, Inorg. Chem. Commu. 11 (2008) 843-846.

[5] C.-S. Liu, Z. Chang, J.-J. Wang, L.-F. Yan, X.-H. Bu, S. R. Batten, Inorg. Chem. Commu. 11 (2008) 889-892.

[6] Z.-L. You, L. Zhang, D.-H. Shi, L.-L. Ni, Inorg. Chem. Commu. 12 (2009) 1231-1233.

[7] K. Nomiya, K. Tsuda, T. Sudoh, M. Oda, J. Inorg. Biochem. 68 (1997) 39-44.

[8] E. Barreiro, J. S. Casas, M. D. Couce, A. Sánchez, R. Seoane, J. Sordo, J. M. Varela, E. M. Vázquez-López, Euro. J. Med. Chem. 43 (2008) 2489-2497.

[9] B. S. Creaven, D. A. Egan, K. Kavanagh, M. McCann, A. Noble, B. Thati, M. Walsh, Inorg. Chim. Acta 359 (2006) 3976-3984.

[10] R. Curran, J. Lenehan, M. McCann, K. Kavanagh, M. Devereux, D. A. Egan, G. Clifford, K. Keane, B. S. Creaven, V. McKee, Inorg. Chem. Commu. 10 (2007) 1149-1153.

[11] N. C. Kasuga, R. Yamamoto, A. Hara, A. Amano, K. Nomiya, Inorg. Chim. Acta 359 (2006) 4412-4416.

[12] R. Rowan, T. Tallon, A. M. Sheahan, R. Curran, M. McCann, K. Kavanagh, M. Devereux, V. McKee, Polyhedron 25 (2006) 1771-1778.

[13] H. J. Klasen, Burns 26 (2000) 117-130.

[14] H. J. Klasen, Burns 26 (2000) 131-138.

[15] M. A. M. Abu-Youssef, V. Langer, L. Öhrström, Dalton Trans. (2006) 2542-2550.

[16] M. A. M. Abu-Youssef, V. Langer, L. Öhrström, Chem. Commu. (2006) 1082-1084.

[17] M. A. M. Abu-Youssef, R. Dey, Y. Gohar, A. A. Massoud, L. Öhrström, V. Langer, Inorg. Chem. 46 (2007) 5893-5903.

[18] A. A. Massoud, V. Langer, Acta Cryst. C65 (2009) m198-m200.

[19] A. A. Massoud, V. Langer, M. A. M. Abu-Youssef, Acta Cryst. C65 (2009) m352-m354.

[20] M. A. M. Abu-Youssef, S. M. Soliman, V. Langer, Y. M. Gohar, A. A. Hasanen, M. A. Makhyoun, A. H. Zaky, L. R. Öhrström, Inorg. Chem. 49 (2010) 9788-9797. 
[21] A. A. Massoud, Y. M. Gohar, V. Langer, P. Lincoln, F. R. Svensson, J. Janis, S. T. Gårdebjer, M. Haukka, F. Jonsson, E. Aneheim, P. Löwenhielm, M. A. M. Abu-Youssef, L. R. Öhrström, NJC (2011) DOI: 10.1039/c0nj00697a

[22] A. A. Massoud, V. Langer, M. A. M. Abu-Youssef, L. Öhrström, Acta Cryst. C67 (2011) m1-m4.

[23] W.-M. Bu, L. Ye, Y.-G. Fan, Inorg. Chem. Commu. 3 (2000) 194-197.

[24] F. Allen, Acta Cryst. B58 (2002) 380-388.

[25] F. Pointillart, P. Herson, K. Boubekeur, C. Train, Inorg. Chim. Acta 361 (2008) 373-379.

[26] G. Marinescu, R. Lescouëzec, D. Armentano, G. De Munno, M. Andruh, S. Uriel, R. Llusar, F. Lloret, M. Julve, Inorg. Chim. Acta 336 (2002) 46-54.

[27] G. A. Bowmaker, Effendy, K. C. Lim, B. W. Skelton, D. Sukarianingsih, A. H. White, Inorg. Chim. Acta 358 (2005) 4342-4370.

[28] P. Kebarle, U. H. Verkerk, Mass Spectrometry Reviews 28 (2009) 898-917.

[29] K. Nomiya, Y. Kondoh, H. Nagano, M. Oda, J. Chem. Soci. Chem. Commu. (1995) 1679-1680.

[30] E. C. Constable, C. E. Housecroft, B. M. Kariuki, M. Neuburger, C. B. Smith, Aust. J. Chem. 56 (2003) 653-655.

[31] I. Starke, S. Kammer, N. Grunwald, U. Schilde, H.-J. Holdt, E. Kleinpeter, Rapid Commun. Mass Spectrom. 22 (2008) 665-671.

[32] Centers for Disease Control and Prevention http://www.cdc.gov/nczved/divisions/dfbmd/diseases/glanders/. 